\title{
Cloud Service: Cost Effective Strategy to Manage Cloud Services
}

\author{
Subashis Biswas \\ Dept. of CSE \\ Netaji Subhash Engineering College, \\ West Bengal, India
}

\author{
Argha Roy \\ Dept. of CSE \\ Netaji Subhash Engineering College, \\ West Bengal, India
}

\author{
Meghdut Roy Chowdhury \\ Dept. of CSE \\ Techno India, \\ West Bengal, India
}

\begin{abstract}
Cloud computing supports an online infrastructure where computing resources are provided as a service over the Internet. This paper proposes a new model exploring the concept of sharing a common infrastructure and service by top to bottom level business organizations to increase business opportunity while providing isolation and security to end-users. User identification IP based security and elasticity, i.e., enabling of variable amount of services to be drawn from the cloud are also provided. The proposed model incorporates Software as a Service (SaaS) which is a rapidly growing model for software licensing.
\end{abstract}

\section{Keywords}

Cloud Computing- Emerging technologies, Data Reliability, Software as a Service, SaaS Model, and Cost Effective Business Model.

\section{INTRODUCTION}

The cloud computing model proposed here is a cost-effective model which aims to establish the worldwide Design, Development, Implementation, success and popularity of the concept of SaaS. Such a model is expected to be highly beneficial for all types of business organizations- Small or Big. With the advancement of modern society, numerous facets of life are moving online thus making the Internet a virtual human society. This has resulted in the emergence of virtual distributed computing. Cloud computing supports this virtualization; it is the use of computing resources (hardware and software) that are delivered as a service over a network. Not only can cloud computing be used in many application scenarios, it is also preferred by smaller organizations as they reap the benefits of not having to deploy physical infrastructure like file, e-mail servers or storage systems. It has evolved from IT system to public service, from costsaving tools to revenue generator, and from ISP to telecom. The main types of public cloud computing are Infrastructure as a Service, Platform as a Service, Software as a Service. Software as a Service (SaaS) is a software distribution model in which is the service is available to customers over the Internet and hosted by a service provider or vendors who manage the infrastructure and platform on which the applications run. SaaS is sometimes referred to as "ondemand software" and is usually priced on a pay-per-use basis. Global accessibility and easier administration are the main benefits of SaaS. The current market scenario showcases that with the advancement of SaaS and the benefits that it brings, the economy of traditional software is already on a

downhill. The dramatic changes brought in by SaaS as documented in trade journals are that SaaS does not require huge investments on the part of the end user. Instead of bringing in vast transactions at one go, it ensures steady cash flow. However, data security becomes an issue since the users' data is stored in the vendors' hardware systems. As reported by trade analysts, "Mid-sized companies plan to continue aggressive expansion into cloud computing in the coming year, as cost reductions and developing capabilities are expected to further entice the overall corporate marketplace". On the basis of these findings we propose a cost effective interface for Business to Customer organizations that often cannot avail a software or service from the traditional markets due to financial constraints. It provides an array of services to the $\mathrm{B} 2 \mathrm{C}$ organization.

\section{EXISTING WORK}

The article begins with a brief introduction to Cloud Computing in universities, referring to the most important results obtained so far. Further, a starting point for universities to use Cloud Computing is provided, by proposing an adoption strategy. The strategy includes five stages, with emphasis on the evaluation of data and processes / unction's/ applications from several major universities based on some key criteria, while creating a correspondence between these aspects and the models/services/applications that exist on the Cloud market. The results obtained are encouraging and support the use of Cloud solutions in universities by improving knowledge in this field and providing a practical guide adaptable to the university's structure. In order to be applicable in practice, the proposed model takes into account the university's architecture and criteria such as mission, availability and importance of applications and also the data's mission, sensitivity, confidentiality, integrity and availability[7]. Cloud Computing is among the recently developed architectures to result to cost effective and reliable way to access resources with the help of emerging technology of VMs i.e. Virtual Machines. In this paper we propose a cost effective way for the subscribers to invest for an e-learning system which otherwise is a very expensive venture. Cloud computing now is the most agile technology after Grid Computing with its limitations of course. The proposal is to use Cloud Computing at its best for the telecom industry. Mobile cloud computing is becoming very popular nowadays which is now removing the use of platform or infrastructure to run applications in their mobile rather use the Saas ,Paas and Iaas features of cloud computing. So in order to access thelearning system from mobiles the end-users depend on their subscribers. Hence the proposal is to give a cost effective way for the subscribers to give access of the e-learning system to their customers.[10] Cloud Consulting combines open source grid computing for distributed cloud computing and 
Enterprise Resource Modeling (ERP) to provide Infrastructure as a Service (IaaS), Platform as a Service (PaaS) and Software as a Service (SaaS) through a simple, unified API[11]. The cloud computing model - especially the public cloud - is unsuited to many business applications and is likely to remain so for many years due to fundamental limitations in architecture and design. Enterprises that move their IT to the cloud are likely to encounter challenges such as security, interoperability, and limits on their ability to tailor their ERP to their business processes [12]. In today' intensely competitive environment, traditional application systems such as ERP, lacks the autonomy and flexibility required by dynamic market. Given that, more and more companies are offering their software by Software as a Service (SaaS) application platform. Most SaaS platforms are implemented by traditional J2EE programming [13]. This research will be looking at applying the Software as a Service (SaaS) model for hosted applications to more complex business systems such as an Enterprise Resource Management System (ERP). This application of the service model is still in its infancy and we present some challenges to the technology. We will initially be developing a measure of complexity for business systems and applying this as a baseline for the use of such complex business systems within a pure SaaS model on the cloud, considering the elements making up SaaS and interrelating these with this definition of business complexity [14].

\section{MAJOR FINDING}

Online relationships in social networks are often based on real world relationships and can therefore be used to infer a level of trust between users. If we analyze the Google mail platform common users are using Google cloud platform for their mail and chat services. But if we review this from the organizational point of view no one will be agree to build this huge infrastructure for their individual company correspondence. This arises due to last infrastructure and maintenance cost. Authentication of the appropriate user is also a challenge. Authentication mechanism allows end users to authenticate themselves by entering the ID and password on the browser and the authentication API that is used by the SaaS providers to create the authentication screen on the SaaS application. A user information browsing screen is also provided. This shows basic information such as the number of registered tenants as well as the numbers of accesses to and the number of users of SaaS applications, the number of common component users and the number of transactions. Maintaining the whole services, modules and users is a big challenge to operate SAAS model.

\section{SCOPE OF WORK}

The term Cloud Computing usually refers to online delivery and consumption model for business and customer services. These include IT services like Software as- a-Service (SaaS) and Storage or Server capacity as a service and many non-IT business and consumer services which are not computing tasks. Clouds represent an inflection point in global distributed software development. Through cloud SaaS model maintaining the proper authentication is huge task. For this reason we need to maintain a cycle to keep the proper user into the proper module where service has been permitted for that particular business organization. One organization can be spread throughout the glob and service modules are respectively distributed according to the organizations' need. Proper user for proper module along with access restriction is the main area of work. According to the operation of various services system needs to generate the analytical report for the registered organization to grow properly. Technology is the key component of this whole task to accomplish the business demand as per organization demand.

\section{PROPOSED SAAS MODEL}

The proposed model is a state-of-the-art SaaS built with a set of cutting-edge web technologies. According to the model, an IT organization owns and operates the SaaS Cloud. This organization is technically termed as the Cloud Service Provider. In this cloud, there a large number of software services (say, service 1 , service 2 , service 3 and so on). Suppose, one of these services is an ERP and it has different modules - Finance (module 1), HR (module 2), Accounts (module 3) and Marketing (module 4). Now, end-user can choose any of the services including all modules as well as some selective modules as per their requirements. Depending on its exact needs, the organization can purchase the suitable module of the software service. Suppose an organization X wants to use this service 1 and $\mathrm{X}$ has office branches throughout the world including Kolkata, Chennai, Mumbai, New Delhi, Bangalore, Melbourne, New York and others. Different branches of $\mathrm{X}$ have different module requirements of the same service (service 1). Suppose, the branch located at Kolkata requires the HR module (module 1), the branch located at Mumbai requires the Accounts module (module 2) whereas the branch located at Melbourne requires the Finance module (module 3) and the branch located at New York requires the Marketing module (module 4). All the different module users are identified by their unique IP addresses. For using these modules, each branch needs to register for the respective module. This entire system functions in such a way that all the use of the Kolkata branch of X cannot be viewed by the Mumbai branch or any other branch of $\mathrm{X}$ unless permitted by the cloud system administrator. Like X, several other organizations can use the same software service. On use, the Cloud System produces a detailed Analysis Report of software service use for each and every organization.

\begin{tabular}{|l|}
\hline Service 1 \\
\hline Service 2 \\
\hline Service 3 \\
\hline Service 4 \\
\hline$\cdot$ \\
\hline. \\
\hline. \\
\hline Service N \\
\hline
\end{tabular}

\begin{tabular}{|l|}
\hline Module 1 \\
\hline Module 2 \\
\hline Module 3 \\
\hline Module 4 \\
\hline$\cdot$ \\
\hline$\cdot$ \\
\hline Module N \\
\hline Service 1
\end{tabular}

Fig 1: Service Architecture

Let's analyze Google Mail which is totally based on Cloud. It is a trust model used by common people throughout the world. If every business organization wants to build their internal e-mail system by their own initiatives it is a havoc task and it is not a cost-effective solution. This is because the same structure needs to be created in different places and they are completely same in nature whereas Gmail provides a very good platform that we are sharing the same infrastructure but completely different storage. Administering such a sophisticated cloud involves huge amounts of Infrastructure Cost, Operation Cost and Maintenance Cost. Thus, a small business enterprise cannot afford to use such an expensive web-based system. This cloud offers highly advanced multi- 
purpose web application software, the functionalities of which include Data Warehousing, Data Mining, Generation of Analytical Reports, etc. According to this model, a single platform offers many software services. According to our SaaS model, every small company can use the same infrastructure and software according to their requirements from their various branches. Not only that, they can choose the software module from their various services as well. We already have given proposed model along with initial identification/authentication of every registered business organization whereas system automatically identifies the business location along with static IP, services, different modules and storage device which is interrelated for every user. For using such a service, a company will be recognized by its NAME and a unique ID. On use, the Cloud System produces a detailed Analysis Report of software service use for each and every organization. To build and administer such a web service is practically too much expensive for a small business organization. In order to purchase and use such service, an organization needs to register as per its own requirements. Due to greatly reduced software expense and infrastructure expense, small organizations using such web service can attain quick phenomenal growth. Hence, the implementation of 'SaaS' is highly beneficial for small to medium organizations. Also to mention, to ensure robustness of this entire cloud system, an authentication table is maintained at the cloud side. This table is showing that which organization is currently using which module and web service.

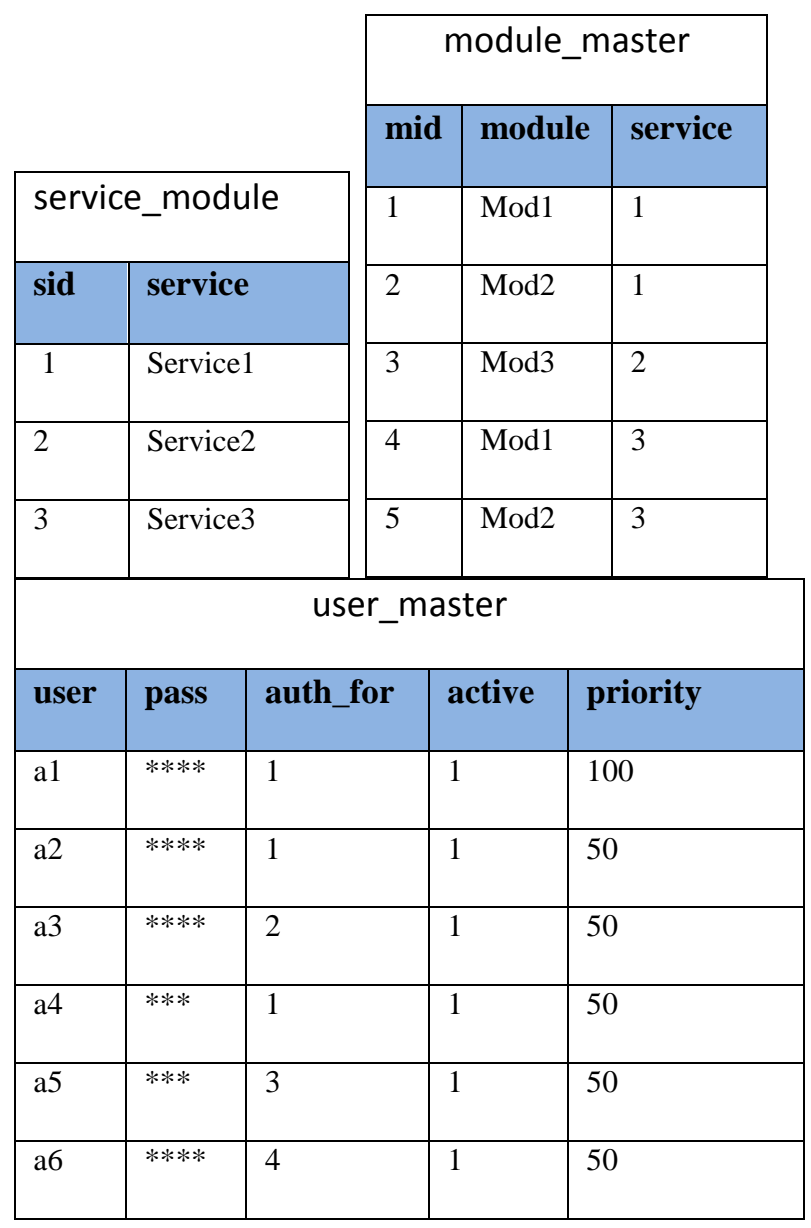
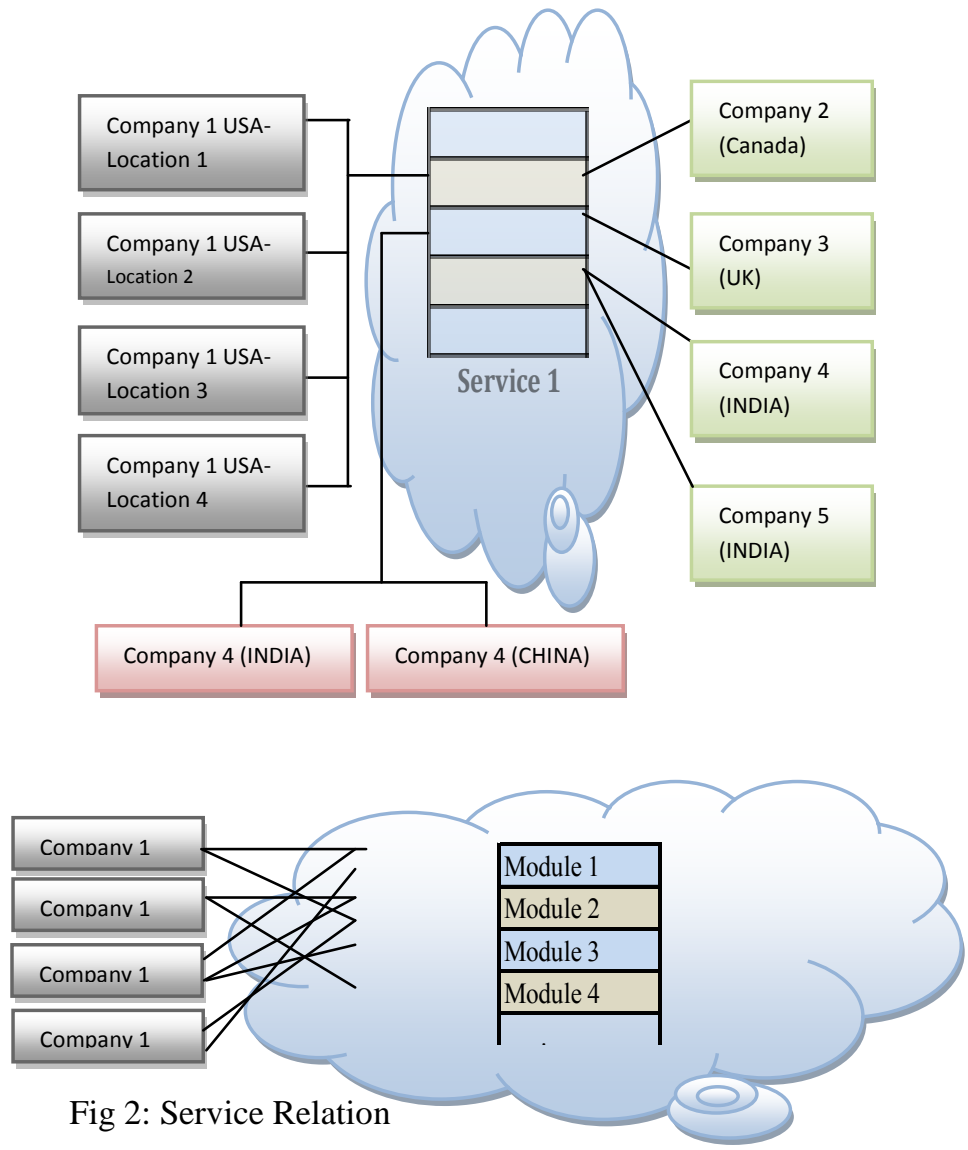

For using a particular module, an organization has to LOG IN to the system with its unique USER ID. This table clearly shows the specific module (s) which already have been authenticated and the specific modules which are been requested for authentication.

\section{DATABASE TABLE}

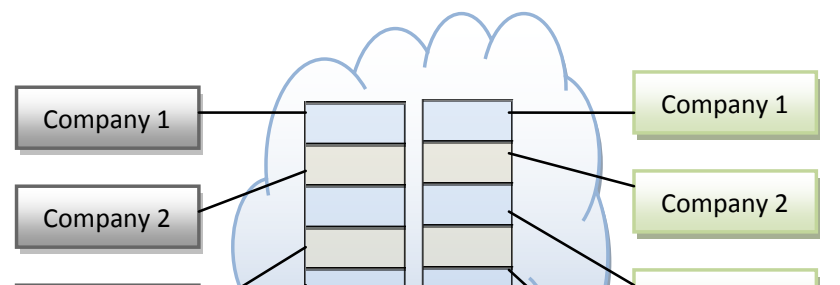


Volume 71-No.9, May 2013

\begin{tabular}{|l|l|l|l|l|l|}
\hline \multicolumn{7}{|c|}{ user_module } \\
\hline ton & id & module & location & ip & storage \\
\hline 1 & 1 & 1 & India & 1.1 .1 .1 & $\mathrm{db} 1$ \\
\hline 2 & 1 & 1 & USA & 1.1 .1 .4 & $\mathrm{db} 2$ \\
\hline 3 & 1 & 2 & China & 2.2 .2 .2 & $\mathrm{db} 3$ \\
\hline 4 & 5 & 5 & India & 3.2 .4 .5 & $\mathrm{db} 4$ \\
\hline 5 & 5 & 5 & India & 1.1 .1 .1 & $\mathrm{Db} 5$ \\
\hline
\end{tabular}

Table service_module is being used for keeping the service information and module_master for segregating the module of every service. Table org_master is keeping the registered organization details, total no of online user and table user_master is keeping the unique user name, password and priority. Table user_module is being user for keeping the location IP and storage path where data will be saved. Here database will be split according to the requirement of the services. Module wise database relationship will be maintained through the user_module table. Priority will grant the permission of user to access the data according to the organizations' administrator. Into the algorithm complete process has been described for this service oriented model.

\section{ALGORITHM}

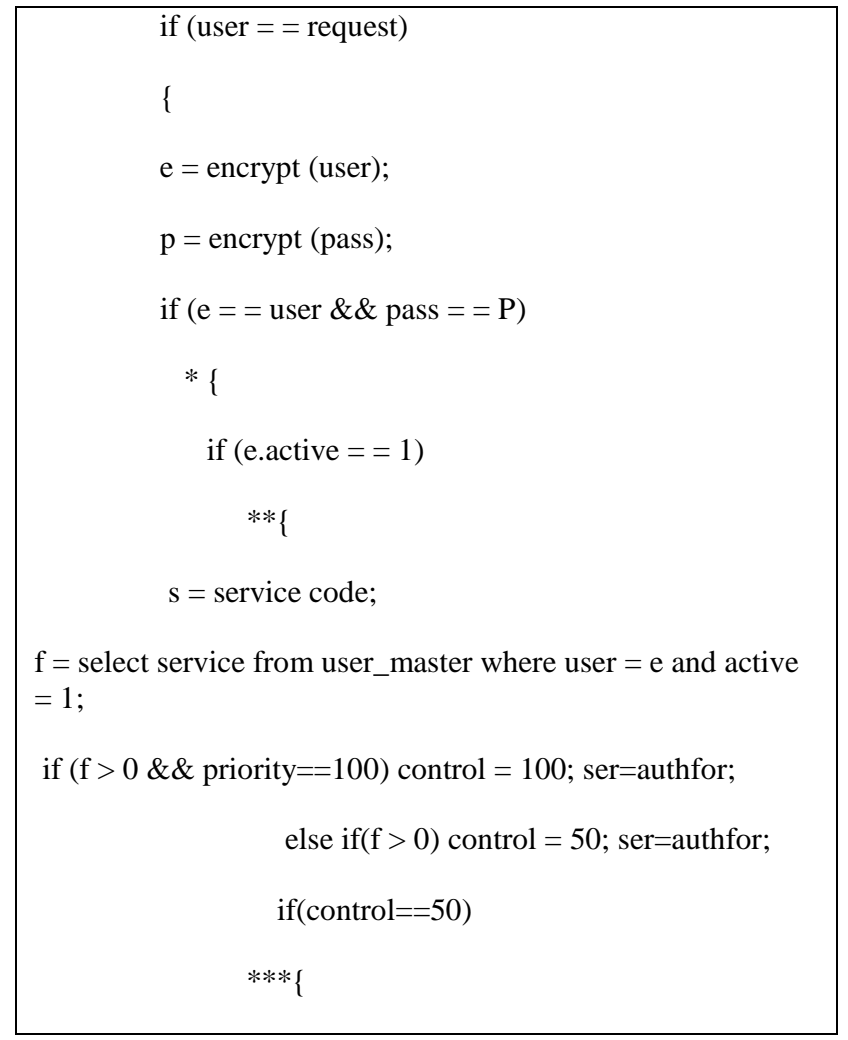

$\mathrm{k}=$ select $*$ from user_module where ton $=$ ser;

while ( mysql_fetch_array)

\{

activemodule $=$ module;

activeip $=\mathrm{ip}$

actived $=$ storage;

$\operatorname{id}[1]=\mathrm{id}$

\}

$\mathrm{z}=$ select $*$ from org_master where orgid $=\mathrm{id}[1]$;

while (mysql_fetch_array)

\{

softservice $=$ service;

activeuser $=$ user;

\}

$$
* * *\}
$$

else

\{

$\mathrm{k}=$ select $*$ from user $\_$module where ton $=\mathrm{ser}$;

while (mysql_fetch_array)

\{

$$
\text { id }[1]=\mathrm{id} \text {; }
$$

$\mathrm{z}=$ select $*$ from org_master where orgid $=\mathrm{id}[1]$;

while ( mysql_fetch_array)

\{

softservice $=$ service;

activeuser $=$ user;

\}

$\mathrm{km}=$ select $*$ from module master where service $=$ softservice;

ty $=0$

while ( mysql_fetch_array)

\{

$\operatorname{id}[\mathrm{ty}]=$ mid; 


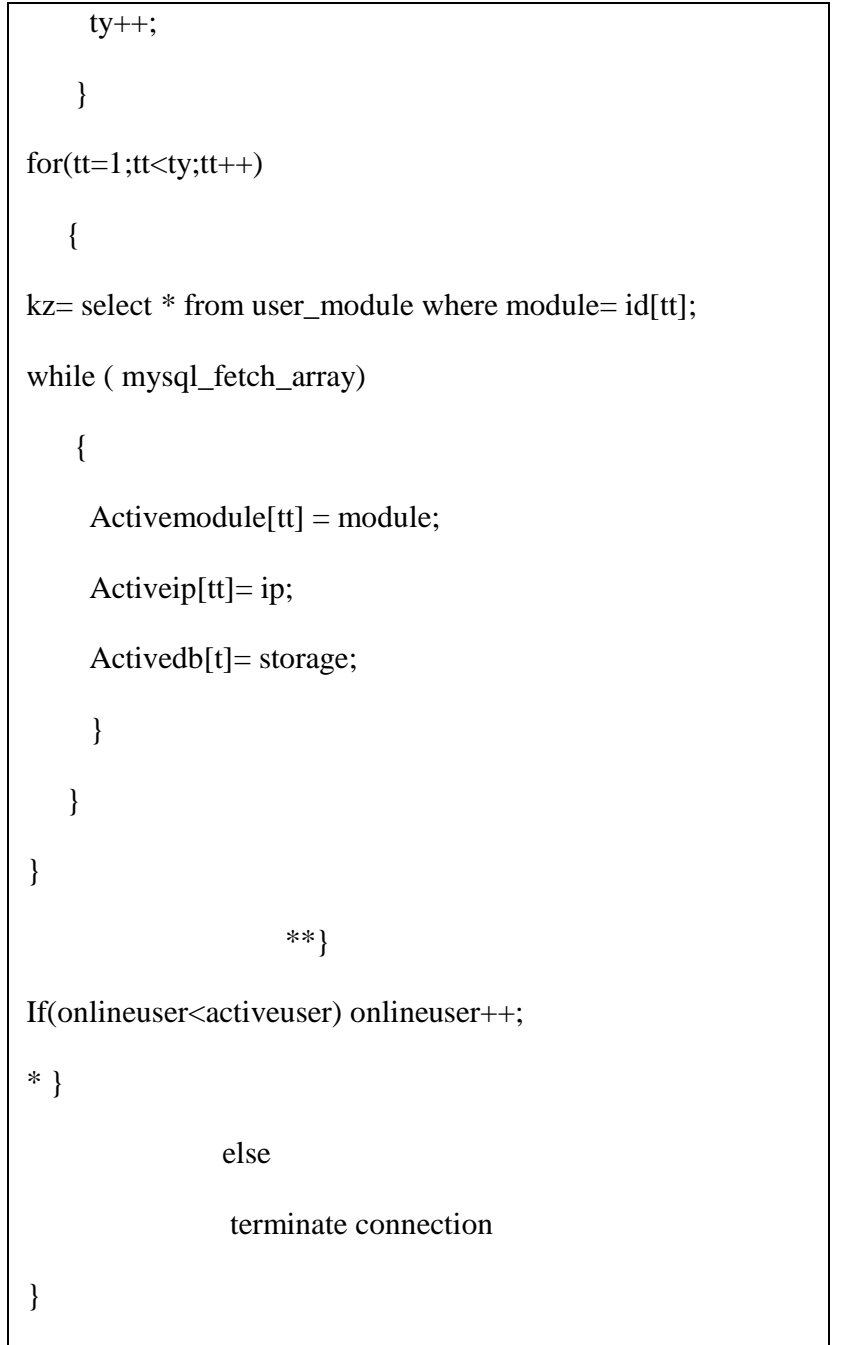

\section{CONCLUSION}

Cloud computing allows consumers and businesses to use applications without installation and access their personal files at any computer with internet access. This technology allows for much more efficient computing by centralizing storage, memory, processing and bandwidth. SaaS is becoming an increasingly prevalent delivery model as underlying technologies that support Web services. Broadband service has become increasingly available to support user access from more areas around the world. All types of business organizations can use this model for meeting their own respective IT requirements at low cost. But one feature of this type of web service to be alert of is that it is totally web based. Hence, failure of internet connection simply implies that this cloud service cannot be used. Thus, in order to properly use this marvelous web service, use of lease line is highly recommended for each and every user. Static IP is mandatory for this web service to effective work. But in this electronic age, since internet connection is affordable for people all over the world, this SaaS will be accessible for users of all parts of the world. If this model of cloud computing is implemented, all the benefits of SaaS can be established worldwide.

\section{REFERENCES}

[1] E. Deelman, G. Singh, M. Livny, J. B. Berriman, and J. Good, "The cost of doing science on the cloud: the Montage example," in SC. IEEE/ACM, 2008, p. 50.

\begin{tabular}{|l|l|l|l|l|}
\hline \multicolumn{5}{|c|}{ org_master } \\
\hline orgid & org & details & user & service \\
\hline 1 & xyz & ---- & 4 & Service1 \\
\hline 2 & mnz & ---- & 10 & Service1 \\
\hline 3 & xy1 & ---- & 12 & Service2 \\
\hline 4 & mnk & ---- & 16 & Service3 \\
\hline 5 & xyz & ---- & 20 & Service3 \\
\hline
\end{tabular}

[2] Amazon Web Services, "Case studies," Amazon web site, Oct 2012,[Online] Available: http://aws.amazon. Com/solutions/case-studies/. Last accessed Oct 2012.

[3] Edna Dias Canedo, Rafael Timóteo de Sousa Junior, and Robson de Oliveira Albuquerque,"TRUST MODEL FOR RELIABLE FILE EXCHANGE IN CLOUD COMPUTING" International Journal of Computer Science \& Information Technology (IJCSIT) Feb 2012.

[4] Monika Sharma, Ashwani Mehra, Haresh Jola, Anand Kumar Dr.Madhvendra Misra, Ms.Vijayshri Tiwari "Scope of cloud computing for SMEs in India" JOURNAL OF COMPUTING,ISSUE 5, MAY 2010, ISSN 2151-9617.

[5] R. H. Saavedra and A. J. Smith, "Analysis of benchmark characteristics and benchmark performance prediction," ACM Trans. Comput. Syst., 1996.

[6] R. Krebs, C. Momm, and S. Kounev, "Metrics and techniques for quantifying performance isolation in cloud environments," in Int'l. ACM SIGSOFT conference Quality of Software Architectures (QoSA), 2012

[7] Marinela Mircea and Anca Ioana Andreescu,"Using C ud Computing in Higher Education: A Strategy to Improve Agility in the Current Financial Crisis", IBIMA PublishingCommunications of the IBIMA http://www.ibimapublishing.com/journals/CIBIMA/cibi ma.html, Vol. 2011 (2011), Article ID 875547, 15 pages.

[8] Amazon Elastic Compute Cloud (EC2), http://www.amazon.com/ec2/ [18 July 2008]

[9] Google App Engine, http://appengine.google.com [18 July 2008].

[10] Subashis Biswas,R. Sravanti,Kumari Khushboo,"COST EFFECTIVE CLOUD STRATEGY TO INCORPORATE E-LEARNING SYSTEM IN TELECOM MEDIUM", IEEE National Conference on Paradigm Shift in Education Technology \& Content Management, E-TCM 2012.

[11] Suciu,G.Telecommun. \& Inf. Technol., Politeh. Univ. of Bucharest, Bucharest, Romania,“Cloud consulting: ERP and communication application integration in open source cloud systems", IEEE Conference, Nov. 2011.

[12] Hofmann, P. SAP Labs, Palo Alto, CA, USA Woods, D.," Cloud Computing: The Limits of Public Clouds for Business Applications”, IEEE Conference, Dec. 2011. 
[13] Xiaoyan Jiang Yong Zhang; Shijun Liu," A Welldesigned SaaS Application Platform Based on Modeldriven Approach", IEEE Conference, Nov. 2010.
[14] Spiteri,K.J. Luca,C.; Reynolds, .; Wilson, G. ," Developing a framework for modeling complex business systems within the cloud", IEEE Conference, June. 2012 